\title{
Relevance of Branding of Green IT for Sustainable Development of IT Companies
}

\author{
Meenakshi Sharma and Anamica Singh
}

\begin{abstract}
Green IT is a buzzword, doing the rounds all over the world these days. Considering today's scenario, we can easily make out the growing awareness of organizations' ecological responsibilities and sustainability.

Also management depicts that sustainability is literally taking a leap to develop environment friendly technologies, also it has been noticed that to solve the sustainability concern, together organizations' green competitive positioning and sustainability less work has been done. Although, not much of researches' has been conducted to explore how Greening Technologies (Green IT), can help organizations attain competitive advantage with branding of Green IT and develop sustainability. The main motive of this paper is to propose a framework with regard to the roles of branding of Green IT in the quest of sustainable development of IT companies. The major objectives of the paper are to find the relevance of Green IT in IT companies and to find an answer for the following questions - What is the relevance of Branding of Green IT? How Green IT can help IT companies in their sustainable development?
\end{abstract}

Index Terms - Branding, green IT, sustainability.

\section{INTRODUCTION}

In a recent report, market research firm Gartner said green IT and sustainability were key concerns for businesses, investors and technologists across industries and policymakers in India. So forth, India will spend US $\$ 45$ billion on green IT and sustainability initiatives this year, and hit US $\$ 70$ billion by 2015 , gratitude to government policies lashing adoption. According to a study by the analyst company, the country's spending on green IT and sustainability initiatives will observe a growth from $\$ 35$ billion in 2010 to $\$ 70$ billion in 2015. In its report titled 'Hype Cycle for Green IT and Sustainability in India, 2012', it was said that green IT and sustainability spending in India would be around $\$ 45$ billion [1].

\section{LiterATURE REVIEW}

The paper tries to focus on Green IT, to promote sustainable development in IT companies. In the past, IT was designed, manufactured, and applied in business enterprises without regard to its environmental impact.

Green IT has the potential to promote sustainability and should be addressed as a strategic [2]. Green IT is the highlight for sustainability, as future generation and future concerns lies in developing environment savvy technologies

Manuscript received October 26, 2012; revised January 21, 2013.

Meenakshi Sharma is with Anamica Singh, BIT Mesra, India (e-mail: meenakshi_pradeep@rediffmail.com). for sustainable organizations. Sustainability "is in the process of becoming a competitive and strategic issue" [3] and it is supposed to cause fundamental shifts in the competitive landscape and create game-changing opportunities [4]. That is why organizations must advance from unfocused investments to consistent sustainability strategies being aligned with core business activities [5]. There is empirical evidence for a positive relationship between corporate responsibility and firm performance [6] even claim that the efficient use of resources is a new paradigm, uniting environmentalism and competitiveness [7].

Although there is general agreement on the strategic relevance of positioning in modern marketing management, the concept of "positioning" itself still lacks a coherent definition [8]. Brand positioning has been analysed both from a strategic standpoint [9] and an analytical perspective [10]. Conceive of positioning as an iterative process, consisting of deliberate and proactive actions aimed at the definition of distinct consumer perceptions. Brand positioning is the part of the brand identity and value proposition that is to be actively communicated to the target audience [11]. Consequently, brand positioning is based on the interaction of all marketing tools, with an accentuated role for marketing communications because of its relevance in the process of shaping distinct consumer perceptions.

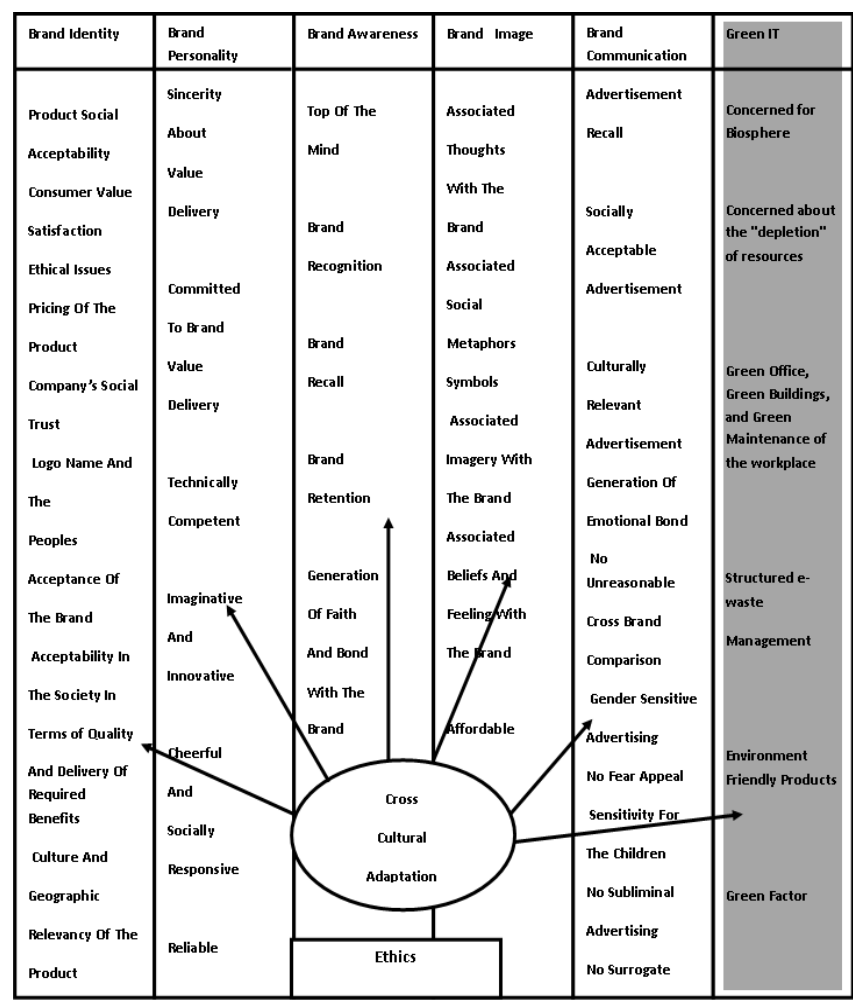

Fig. 1. Ethical Brand Positioning Framework 
Thus, positioning a brand as a "green brand" entails an active communication and differentiation of the brand from its competitors through its environmentally sound attributes. Ecologically sustainable products will not be commercially successful if green brand attributes are not effectively communicated [12]. Suggest by two researchers' that green positioning as an essential factor in the success of green branding strategies [13]. Following classification schemes of generic positioning strategies, a brand can be positioned by functional attributes and/or by emotional benefits. Green brand positioning strategies are here classified as functional or emotional.

Ethical brand positioning framework (Fig. 1): A research paper by Mahim sagar, Deepali singh and D P aggarwal addresses ethical brand positioning concept and elaborated five basic elements of brand positioning namely- Brand identity, Brand image, Brand awareness, Brand personality, Brand awareness, Brand communication [14].

The framework is further used in this paper and has used "Green IT" as one of the branding strategies of IT companies.

\section{THE RESEARCH APPROACH}

After analyzing statistically significant framework a predictive framework is developed. In this framework EBP is taken as dependent variable on five elements (brand image, brand awareness, brand identity, brand communication, brand personality, green IT) which are taken as independent variables as more than two it is multivariate regression framework and can be represented in the following way -

$\mathrm{EBP}=$ Brand image + Brand awareness + Brand identity + Brand communication + Brand personality + Green IT

The study contributes a new concept and terminology in the field of brand management that is "Ethical Brand Positioning" (EBP).

Framing of hypothesis: To observe the independence of the branding variables and ethical brand positioning following hypothesis were framed-

$\mathbf{H}_{\mathbf{0 a}}$ : Brand identity does not have significant role in developing ethical brand positioning of an IT company.

$\mathbf{H}_{\mathbf{0 b}}$ : Brand personality does not have significant role in developing ethical brand positioning of an IT company.

$\mathbf{H}_{\mathbf{0 c}}$ : Brand awareness does not have significant role in developing ethical brand positioning of an IT company.

$\mathbf{H}_{\mathbf{0 d}}$ : Brand communication does not have significant role in developing ethical brand positioning of an IT company.

$\mathbf{H}_{\mathbf{0}}$ : Brand image does not have significant role in developing ethical brand positioning of an IT company.

$\mathbf{H}_{\mathbf{0 f}}$ : Green IT does not have significant role in developing ethical brand positioning of a IT company. Hypothesis testing was done with the help of Pearson correlation.

Questionnaire design: the first part four general questions about the respondent like name, age, occupation and gender. Second part had questions related to companies in six areas brand identity, brand image, brand awareness, brand personality, brand communication, Green IT. Please refer to Appendix. The chosen well-known IT brands taken into consideration were Dell, Wipro, Intel, IBM, and HP. For each brand, the entire five hypotheses were tested and a correlation analysis was performed on the same. A consolidated significance table in given below for reference and to understand the results drawn during the study of the brands selected. The sample size is 250 and the data has been collected from 50 employees of each IT company using random sampling.

\begin{tabular}{|c|c|c|c|c|c|c|}
\hline Brands & $\begin{array}{l}\text { Brand } \\
\text { identity }\end{array}$ & $\begin{array}{c}\text { Brand } \\
\text { personality }\end{array}$ & $\begin{array}{c}\text { Brand } \\
\text { awareness }\end{array}$ & $\begin{array}{c}\text { Brand } \\
\text { communication }\end{array}$ & Brand image & Green IT \\
\hline Dell & $\begin{array}{l}r=0 \\
.139\end{array}$ & $r=0.622$ & $r=0.778$ & $r=0.628$ & $r=0.705$ & $r=0.555$ \\
\hline Wipro & $r=0.293$ & $r=0.641$ & $r=0.479$ & $r=0.216$ & $r=0.216$ & $r=0.243$ \\
\hline Intel & $r=0.237$ & $r=0.565$ & $r=0.126$ & $r=0.400$ & $r=0.240$ & $r=0.065$ \\
\hline IBM & $r=0.506$ & $r=0.358$ & $r=0.666$ & $r=0.516$ & $r=0.166$ & $r=0.100$ \\
\hline HP & $r=0.576$ & $r=0.089$ & $r=0.531$ & $r=0.581$ & $r=0.602$ & $r=0.518$ \\
\hline
\end{tabular}

\section{THE RESEARCH APPROACH}

A. Questionnaire Analysis for the Brands Selected in the Study is depicted in Table I.

Dell - Hypothesis $\mathbf{H}_{\mathbf{0 a}}$ : was rejected as the value of $\boldsymbol{r}=$ 0.139, which indicated that they possess strong positive relation in case of Dell as a brand. It also denotes that Dell possess a strong brand identity of offering value satisfaction to consumers. Hypothesis $\mathbf{H}_{\mathbf{0 b}}$ : was rejected as the value of $\boldsymbol{r}$ $\mathbf{0 . 6 2 2}$, which suggests that there may be a significant positive relation between EBP and brand personality of Dell. By the result we can make out Dell is sincere about value delivery is imaginative and innovative with the customization feature. Hypothesis $\mathbf{H}_{\mathbf{0}}$ : was rejected as the value of $\boldsymbol{r}=\mathbf{0 . 7 7 8}$ brand awareness and ethical brand positioning possess significant relation. Dell is very well known brand in terms of laptops, and in providing IT services that satisfy customer's requirements. Hypothesis $\mathbf{H}_{\mathbf{0 d}}$ : was rejected as the value of $\boldsymbol{r}$ $=\mathbf{0 . 6 2 8}$ which represents a significant relationship between brand communication and ethical brand positioning of Dell. Dell laptops have cheerfully and cross-culturally communicated and made their space in the global market, displaying relevant advertisement for the generation of emotional bond with the customers. Hypothesis $\mathbf{H}_{\mathbf{0 e}}$ is rejected as the value of $\boldsymbol{r}=\mathbf{0 . 7 0 5}$ in case of ethical brand positioning and brand image which denotes a significant relation between the two. Hypothesis $\mathbf{H}_{\mathbf{0 f}}$ is rejected as the value of $\boldsymbol{r}=\mathbf{0 . 5 5 5}$ which means there may be a significant relation between EBP and Green IT. Dell has shown concern for environments and also spreading a word about environmental concern to its customers by making its products and operations greener.

Wipro - Hypothesis $\mathbf{H}_{0 \mathbf{0}}$ is rejected as the value of $\boldsymbol{r}$ $\mathbf{0 . 2 9 3}$, it indicates there may be a significant relation between brand identity and EBP in case of Wipro. Wipro has made its presence by offering reliable and acceptable 
products in society. Hypothesis $\mathbf{H}_{\mathbf{0 b}}$ : is rejected as the value of $\boldsymbol{r}=\mathbf{0 . 6 4 1}$, which indicates that there may be a significant relation between EBP and brand personality. When it comes to Wipro personality, the brand has shown commitment to brand delivery and reliable. Hypothesis $\mathbf{H}_{0 \mathrm{c}}$ is rejected as the value of $\boldsymbol{r}=\mathbf{0 . 4 7 9}$, which indicates that there may be a significant relation between EBP and brand awareness. For customers when buy products, Wipro has been on the top of their mind. Hypothesis $\mathbf{H}_{\mathbf{0 d}}$ : is rejected as the value of $\boldsymbol{r}$ $\mathbf{0 . 2 1 6}$, which indicates that there may be a significant relation between EBP and brand communication. With the idea of apply your thoughts they have communicated culturally. Hypothesis $\mathbf{H}_{0 \mathrm{e}}$ is rejected as the value of $\boldsymbol{r}=\mathbf{0 . 2 1 6}$, which indicates that there may be a significant relation between EBP and brand image. Affordable and trust worthy are the words attached to Wipro's brand image. Hypothesis $\mathrm{H}_{0 \mathrm{f}}$ is rejected as the value of $\boldsymbol{r}=\mathbf{0 . 2 4 3}$, which indicates that there may be a significant relation between EBP and Green IT. Wipro has shown Biological concern and started to work for it by Green computing methods.

Intel - Hypothesis $\mathbf{H}_{\mathbf{0 a}}$ is rejected as the value of $\boldsymbol{r}=\mathbf{0 . 2 3 7}$, which indicates that there may be a significant relation between EBP and brand identity. Intel was focused on standards-based provisioning and strong authentication requirements for service-oriented architecture- based environments that enable administrators to securely manage multiple independent identities on a single Intel platform. Hypothesis $\mathbf{H}_{\mathbf{0 b}}$ is rejected as the value of $\boldsymbol{r}=\mathbf{0 . 5 6 5}$, which indicates that there may be a significant relation between EBP and brand personality. One of its first Internet-based ads focuses on Ajay Bhatt, one of the principal engineers of Intel behind the development of USB, a crucial Intel technology used in virtually all PCs today. Hypothesis $\mathbf{H}_{\mathbf{0 c}}$ is rejected as the value of $\boldsymbol{r}=\mathbf{0 . 1 2 6}$, which indicates that there may be a significant relation between EBP and brand awareness. Earlier the brand had little name recognition amongst end users, despite the fact that Intel microprocessors were the "brains" inside their PCs. Hypothesis $\mathbf{H}_{\mathbf{0 d}}$ is rejected as the value of $\boldsymbol{r}=\mathbf{0 . 4 0 0}$, which indicates that there may be a significant relation between EBP and brand communication. Intel communicated truly with effective ingredient status of the microprocessor. Hypothesis $\mathbf{H}_{\mathbf{0 e}}$ is rejected as the value of $\boldsymbol{r}=\mathbf{0 . 2 4 0}$, which indicates that there may be a significant relation between EBP and brand image. Intel was then soon had a strong image in the global market. Hypothesis $\mathbf{H}_{\mathbf{0 f}}$ is rejected as the value of $\boldsymbol{r}=\mathbf{0 . 0 6 5}$, which indicates that there may be a significant relation between EBP and Green IT. Intel showed its concern for environment by taking up green IT initiatives.

IBM - Hypothesis $\mathbf{H}_{\mathbf{0}}$ : is rejected as the value of $\boldsymbol{r}=\mathbf{0 . 5 0 6}$, which indicates that there may be a significant relation between EBP and brand identity. IBM expressed its identity by personal or character terms - trustworthy, energetic, assertive, unpretentious, arrogant, friendly, and being helpful Hypothesis $\mathbf{H}_{\mathbf{0 b}}$ : is rejected as the value of $\boldsymbol{r}=\mathbf{0 . 3 5 8}$, which indicates that there may be a significant relation between EBP and brand personality. IBM brand was seen as a strong IT competitor and service provider. Hypothesis $\mathbf{H}_{\mathbf{0 c}}$ is rejected as the value of $\boldsymbol{r}=\mathbf{0 . 6 6 6}$, which indicates that there may be a significant relation between EBP and brand awareness. IBM awareness about brand was shown through brand recognition and retention. Hypothesis $\mathbf{H}_{\mathbf{0 d}}$ is rejected as the value of $\boldsymbol{r}=\mathbf{0 . 5 1 6}$, which indicates that there may be a significant relation between EBP and brand communication. Hypothesis $\mathbf{H}_{\mathbf{0}}$ : is rejected as the value of $\boldsymbol{r}=\mathbf{0 . 1 6 6}$, which indicates that there may be a significant relation between EBP and brand image. Hypothesis $\mathbf{H}_{\mathbf{0 f}}$ is rejected as the value of $\boldsymbol{r}=\mathbf{0 . 1 0 0}$, which indicates that there may be a significant relation between EBP and Green IT. IBM contributed for Green environment by 'green' data centres that consume less energy.

HP - Hypothesis $\mathbf{H}_{\mathbf{0 a}}$ is rejected as the value of $\boldsymbol{r}=\mathbf{0 . 5 7 6}$, which indicates that there may be a significant relation between EBP and brand identity. HP builds credibility and loyalty. Hypothesis $\mathbf{H}_{\mathbf{0 b}}$ i is rejected as the Value of $\boldsymbol{r}=\mathbf{0 . 0 8 9}$, which indicates that there may be a significant relation between EBP and brand personality. HP personality was seen as if they were consummate innovators and entrepreneurs. Hypothesis $\mathbf{H}_{\mathbf{0}}$ : is rejected as the value of $\boldsymbol{r}=\mathbf{0 . 5 3 1}$, which indicates that there may be a significant relation between EBP and brand awareness. HP's campaign has increased massively. Hypothesis $\mathbf{H}_{\mathbf{0 d}}$ is rejected as the value of $\boldsymbol{r}$ $=\mathbf{0 . 5 8 1}$, which indicates that there may be a significant relation between EBP and brand communication. HP Rich Communication suite, HP Entertainment \& Communities solutions help you transform the subscriber experience to strengthen its brand. Hypothesis $\mathbf{H}_{\mathbf{0 e}}$ is rejected as the value of $\boldsymbol{r}=\mathbf{0 . 6 0 2}$, which indicates that there may be a significant relation between EBP and brand image. HP brand in PC market and makes use of Compaq and is working to improve its image. Hypothesis $\mathbf{H}_{\mathbf{0 f}}$ is rejected as the value of $\boldsymbol{r}=\mathbf{0 . 5 1 8}$, which indicates that there may be a significant relation between EBP and Green IT. HP's green business initiatives for green IT, energy efficient computing, and IT recycling.

\section{ACKNOWLEDGMENT}

I am greatly thankful to dr. mahim sagar (iit delhi), prof. dr. deepali singh (abv- iiitm gwalior) to give me an INSIGHT OF the topic through the theoretical knowledge as well as through practical knowledge and for the motivation and valuable guidance to write this paper.

\section{REFERENCES}

[1] Gartner Report, "Hype Cycle for Green IT and Sustainability in India," 2012.

[2] E. Zarrella, "Sustainable IT - The Case for Strategic Leadership," KPMG, Zürich, 2008.

[3] J. Elkington, "Cannibals with forks: the triple bottom line of the 21 st century," Capstone, Oxford, 1997.

[4] S. Dutta and I. Mia, "The global information technology report 2009-2010 - ICT for sustainability," INSEAD and World Economic Forum, Geneva, 2010.

[5] D. A. Lubin and D. C. Esty, "The sustainability imperative - lessons for leaders from previous game-changing megatrends," Harvard Business Review, vol. 88, no. 5, pp. 42-50, 2010.

[6] Funk, H. Milstein, K. McLaughlin, and P. LINDE, "Sustainability and Performance," MIT Sloan Management Review, vol.44, no. 2, pp. 65-70.

[7] F. Loeser, K. Erek, N. H. Schmidt, R.Zarnekow, and L. M. Kolbe, in Proc. the Seventeenth Americas Conference on Information Systems, Detroit, Michigan, August 4-7, 2011.

[8] D. A. Aaker and J. Shansby, "Positioning Your Product," Business Horizions, pp. 56-62, May-June, 1982. 
[9] A. L. Ries and J. Trout, Positioning: The Battle for Your Mind, McGraw-Hill, London, 1986

[10] Hauser and Koppelman, Brand positioning- analytical perspective. "Alternative perceptual mapping techniques: relative accuracy and usefulness," Journal of Marketing Research, vol. 16 No. 4, pp. 495-506, 1979.

[11] S. P. Kalafatis, M. H. Tsogas, and C. Blankson, "Positioning strategies in business markets", Journal of Business \& Industrial Marketing, vol. 15, no. 6, pp. 416-37, 2000.

[12] G. M. Pickett, N. Kangun, and S. J. Grove, "An examination of the conserving consumer: implications for public policy formation in promoting conservation behaviour," in Polonsky, M. J. and Mintu-Wimsatt, A. T. (Eds), Environmental Marketing: Strategies, Practice, Theory, and Research, The Haworth Press, New York, NY, pp. 77-99, 1995.

[13] Coddington, Meffert and Kirchgeorg, Environmental Marketing, McGraw-Hill, New York, NY, 1993.

[14] M. Sagar, D. Singh, and D. P. Agrawal, Framework for ethical brand positioning, 2006.

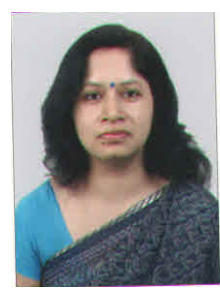

Meenakshi Sharma was born in India on 03/04/1968. She earned her Master's (MBA) in Marketing in the year 1989 from Motilal Nehru Institute of Research \& Business Administration (MONIRBA), Allahabad, India and doctoral degree in Management, from Birla Institute of Technology, Mesra (India) in the year 2011. She has an extensive experience of more than 15 years as a core faculty at various management institute of repute. Presently she is working as an Assistant Professor with Birla Institute Of Technology, Extension Centre, Noida.

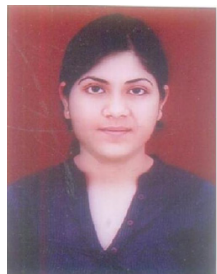

Anamica Singh was born in Noida (India) on $18 / 04 / 1986$. She has earned her Bachelor degree in 2008 from J.S.S.A.T.E (Uttar Pradesh Technical University, Lucknow (India)) and her MBA degree in 2010 from ABV-IIITM, Gwalior. Currently she is pursuing her doctoral degree in Management from Birla Institute of Technology, Mesra, India. 